\title{
Operation Strategy for a Power Grid Supplied by $100 \%$ Renewable Energy at a Cold Region in Japan
}

\author{
Jorge Morel', Shin'ya Obara, Yuta Morizane \\ Department of Electrical and Electronic Engineering, Kitami Institute of Technology, Japan \\ e-mail: jmorel@mail.kitami-it.ac.jp
} http://dx.doi.org/10.13044/j.sdewes.2014.02.0022

\begin{abstract}
This paper presents an operation strategy for a power system supplied from $100 \%$ renewable energy generation in Kitami City, a cold region in Japan. The main goal of this work is the complete elimination of the $\mathrm{CO}_{2}$ emissions of the city while keeping the power frequency within prescribed limits. Currently, the main energy related issue in Japan is the reduction of $\mathrm{CO}_{2}$ emissions without depending on nuclear generation. Also, there is a need for the adoption of distributed generation architecture in order to permit local autonomous operation of the system by the local generation of power. As a solution, this paper proposes a strategy to eliminate $\mathrm{CO}_{2}$ emissions that considers digital simulations using past hourly meteorological data and demand for one year. Results shows that Kitami City can be supplied entirely by renewable generation, reducing its $\mathrm{CO}_{2}$ emission to zero while keeping the quality of its power grid frequency within permitted limits.
\end{abstract}

\section{KEYWORDS}

Renewable energy, Wind power, Solar power, Tidal power, Storage system, Frequency control, Smart grid.

\section{INTRODUCTION}

Concerns about the adverse effects of global warming on the environment and the need of sustainable use of energy resources have been driving governments around the world in the definition of policies regarding the reduction of $\mathrm{CO}_{2}$ emissions through the utilization of renewable energy sources. The USA and the European Union have been leading the development of clean and sustainable energy technologies by the implementation of specific policies and targets $[1,2]$.

One of the technologies applied in power engineering that will allow the interconnection of large numbers of intermittent renewable sources, such as wind and solar, is the smart grid. Besides the possibility of interconnection of variable output renewable generators, smart grids offer other benefits such as active participation of customers in the control of the peak demand of the entire system as well as increased customer participation in the electricity market [3].

Japan, due to its strong and reliable power system, has been focusing mainly on nuclear power to achieve the $\mathrm{CO}_{2}$ emission targets. The Fukushima Daiichi nuclear disaster revealed the real limitations of the system. Furthermore, forced by a strong public opinion resisting nuclear power generation, Japan now has the challenge to rebuild and adapt its power system based mainly on the deployment of intermittent and clean

\footnotetext{
* Corresponding author
} 
renewable energy generation, with a less centralized architecture to increase its reliability in the case of natural disasters.

Tohoku Fukushi University's experimental microgrid in Sendai City demonstrated how important microgrids can be for a country frequently menaced by natural disasters. The microgrid was directly affected by the disaster and it showed resilience [4]. The Japanese government has now established policies to achieve a more reliable and resilient power system [5]. Another important benefit of constructing a self-sufficient microgrid is the reduction of long distance power transfer from centralized power plants, reducing losses and congestion in the transmission lines.

In a cold region, such as Kitami, where there is significant variability in seasonal demand with marked low consumption in summer and high demand in winter, there is a need to shift surplus renewable generation from summer to winter. Storage systems or a coordinated operation with the local power utility should be considered. It is also important to grasp the variability of the total supply considering the type and proportion of each intermittent generation. For example, solar photovoltaic power output changes much faster than a wind turbine power output due to lack of inertia in photovoltaic systems. Also, a tidal farm power output is lower and much more predictable in the long and medium term, comparing to that of a wind farm.

Development of energy systems, that considers a range of infrastructure, such as transport, heat and electricity, has been studied for an optimal design in a given region to create a sustainable energy supply system, reduce $\mathrm{CO}_{2}$ emissions and utilize intermittent renewable generation. Among the leading research groups in this area is Aalborg University in Denmark that has developed an energy system analysis tool called EnergyPLAN and performed the design of energy systems for specific regions in Europe [6-9].

Japanese industry and academia, due to the reasons previously addressed (reliable power grid and focus on nuclear power) have shown relatively slower development on smart or microgrid technologies before the nuclear disaster in 2011. However, a major effort has been put in from the beginning by certain research groups [4, 10, 11]. After the nuclear disaster of 2011, research activities on independent microgrids for local generation and local consumption, containing sustainable renewable energy generation such as wind, solar and tidal power have increased considerably. Operation of microgrids, aiming at the reduction of $\mathrm{CO}_{2}$ emissions and the safety of energy supply, in cold, urban and remote areas has been studied [12-14].

The more rapid oscillations of renewable generator outputs in a microgrid makes the utilization of fast acting batteries necessary to match instantaneous imbalances, in contrast with a traditional power grid where the outputs of the generation units can be controlled and match the slower-changing aggregated demand. The utilization of sodium-sulfur (NAS) batteries was mainly analysed in the past for suppressing instantaneous or fast changing impacts in the grid, including the possibility of independent active and reactive power control in this type of storage systems [15].

On a longer time frame, more availability of resources during certain seasons and low demand in the same seasons lead to surplus energy that may be stored for future use when needed. For this case, storage systems have been analysed for economic benefit and environmental impacts [16, 17]. In Reference [16], NAS batteries are compared to a storage system based on organic chemical hydride but the dynamic performance (fast charging/discharging capability) of the NAS battery was not analysed. In [17], a system with no storage system is analysed. Here, good $\mathrm{CO}_{2}$ reductions are obtained despite the absence of battery storage. However, for a $100 \%$ renewable supply, batteries may be 
necessary to shift energy between seasons or to keep frequency balance, as well as to compensate for any transient faults in the system.

For a complete analysis of a power grid, consideration of dynamic properties of supply and demand is of vital importance. All the energy system designs mentioned above do not consider this aspect.

This work demonstrates that a medium size city located in a cold region, with particular annual load characteristics, can be supplied entirely by renewable energy, reducing completely its $\mathrm{CO}_{2}$ emission without negatively affecting the electricity quality of the system, and completely breaking its dependence on nuclear power generation.

\section{SYSTEM UNDER STUDY}

\section{Location}

Kitami City is located in a cold region, on the Hokkaido Island in the northern part of Japan, as shown in Figure 1. Kitami has an annual demand characteristic with a high heat-to-power demand ratio during winter. The temperature reaches a minimum of $-20{ }^{\circ} \mathrm{C}$ in winter and a maximum of $35^{\circ} \mathrm{C}$ in summer. Despite the low temperature in winter, the city gets little rainfall and snowfall. The city has rich natural resources such as wind, solar and tidal power that can be utilized for the generation of clean electrical energy. It is one of the richest areas in solar irradiation in Japan. Also, it has open areas with good average wind speeds which can also be exploited for the generation of electricity. Furthermore, the Saroma Lake tidal current speeds offer the possibility of exploitation of tidal generation [18].

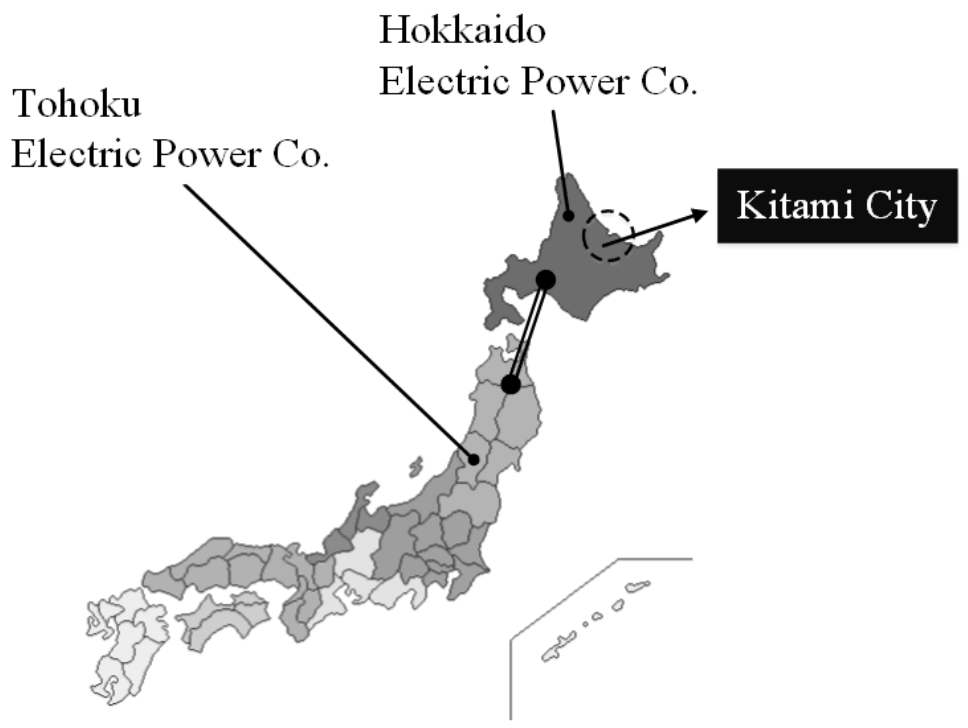

Figure 1. Kitami City location

\section{Transmission network}

The Japanese power system consists of ten power companies that supply energy to specific and semi-independent regions. They are interconnected (except Okinawa Electric Power Company) through transmission lines with limited capacities. The Hokkaido Electric Power Company (HEPCO), shown in Figure 1, with a total installed capacity of 7,500 MW, supplies power to the Hokkaido Island, where Kitami City is located. HEPCO is connected to Tohoku Electric Power Company, located in Honshu, the main island of Japan, by a High-Voltage Direct Current (HVDC) transmission system (indicated by a double line in Figure 1), with a capacity of $600 \mathrm{MW}$, approximately 8\% of HEPCO's total installed capacity [19]. 
The power system of Kitami City is connected to the local utility HEPCO which currently provides the power for the entire city.

The simplified scheme of the Kitami's power system considered for simulation, including the proposed location of renewable generators and storage systems is depicted in Figure 2. The names and rated capacities of the substations are shown in Table 1.

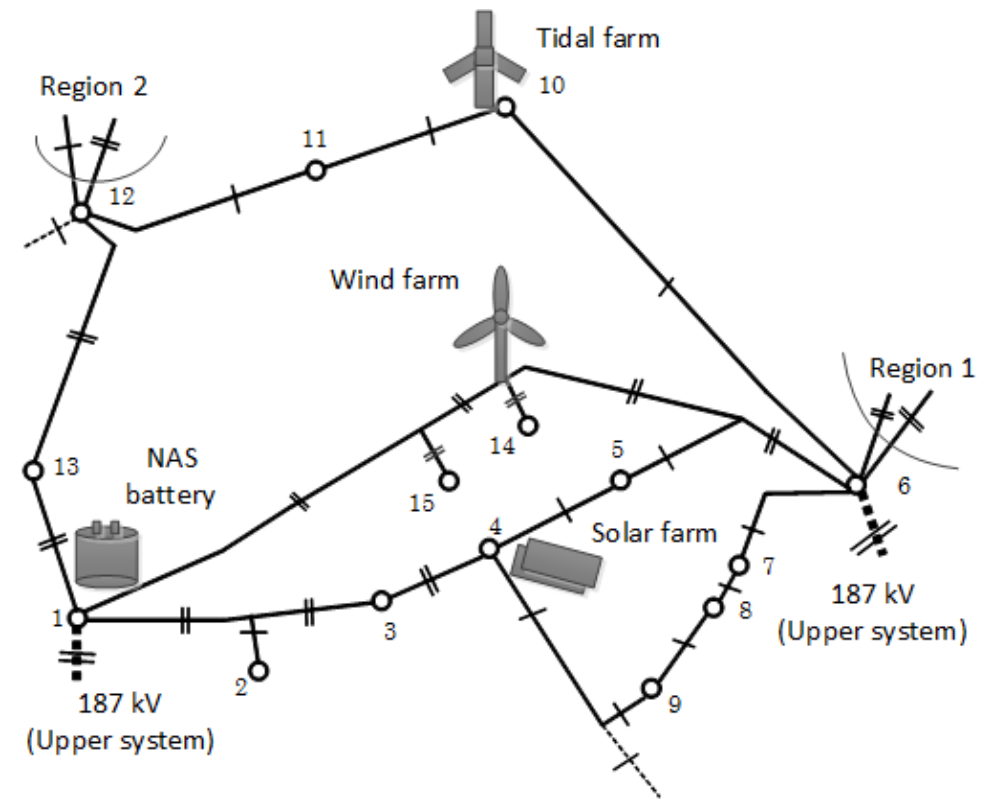

Figure 2. Power system of Kitami City

Selection of the location of the renewable generators was made based on the available resources in the area. Location of the NAS batteries was selected to be the Rubeshibe substation where the bulk power is coming from the conventional power plants of HEPCO. This selection has no direct effect on the results of frequency quality presented in this paper because of the short distances involved. However, from an economic point of view, the most appropriate locations and sizes must be carefully considered.

Table 1. Substation rated capacities

\begin{tabular}{ccc}
\hline No. & Name & Capacity (MVA) \\
\hline 1 & Rubeshibe & 280 \\
2 & Kuneppu & 6 \\
3 & Kitaminishi & 20 \\
4 & Kitami & 35 \\
5 & Tabata & 22 \\
6 & Memanbetsu & 200 \\
7 & Bihoro & 20 \\
8 & Inami & 10 \\
9 & Tsubetsu & 12 \\
10 & Tokoro & 12 \\
11 & Saroma & 10 \\
12 & Engaru & 18 \\
13 & Ikutahara & 3 \\
14 & Kiyomi & 30 \\
15 & Ainonai & 12 \\
\hline
\end{tabular}


As shown in Figure 2, there are mainly two points of connection to the local utility: The Rubeshibe and the Memanbetsu substations.

Each of them is supplied by a double-circuit transmission line of $187 \mathrm{kV}$. Region 1 and Region 2 shown in this figure are two systems with no generating units. The total load for Region 1 is 124 MVA and that for Region 2 is 87 MVA. The two thin dashed lines represent the two weak connections to other systems which are not considered in this work. The small circles represent substations and single or double-circuit transmission lines are indicated by one or two short transverse lines over the lines connecting the substations. All lines are overhead, with rated voltage of $66 \mathrm{kV}$, and short, with lengths of less than $40 \mathrm{~km}$. Typical tower and conductor data for $66 \mathrm{kV}$ transmission line is considered. Each substation is composed of $66 \mathrm{kV} / 6.6 \mathrm{kV}$ step-down transformers with the rating indicated in Table 1 . The reactive power parts of the loads are assumed to be compensated because they do not affect the frequency analysis.

\section{Renewable generation}

Wind power. Currently, most of wind turbines (WTs) in the market are variable-speed types: Doubly-Fed Induction Generator (DFIG) and Full-Scale Converter types, which are capable of independently controlling active and reactive power injected to the system. In this work, the wind farm is simulated using an aggregated model of DFIG-based WTs, modelled by Matlab/Simulink.

Solar power. Photovoltaic type solar farms are considered. They are connected to the transmission network via inverters which have the capability of controlling, independently, the amount of reactive power injected to the network for voltage regulation purposes. For frequency study purposes the faster dynamics are not considered; the solar farm is modelled in this work as a first order system with a short time constant of 10 microseconds.

Tidal power. Horizontal axis tidal turbines are considered [20]. They have similar structure and working principle as the WTs. For short-term frequency studies it can be assumed that the turbines have constant power output. For long-term studies the variability can be forecast with a high degree of accuracy. The tidal farm is simulated using an adapted version of the DFIG-based WT. These assumptions are valid due to the similarity between the wind and tidal generation systems and the time scale considered for simulation.

In this paper, only the highly variable power output of the wind and solar farms are simulated as perturbations to the system due to their higher relative outputs and variability compared to those of the tidal farm.

The parameters of the renewable generators are shown in Table 2.

Table 2. Aggregated renewable generator parameters

\begin{tabular}{ccc}
\hline Generation & Rated capacity (MVA) & Point of connection (No.) \\
\hline Wind Farm & 150 & Kiyomi (14) \\
Solar Farm & 100 & Kitami (4) \\
Tidal Farm & 1.5 & Tokoro (10) \\
\hline
\end{tabular}

\section{Storage systems}

For long-term energy storage aiming at the seasonal and daily energy shift, a storage system with slow dynamics but with high energy density is utilized. For seasonal energy shifting, an organic chemical hydride type system is employed [16]. 
For instantaneous and fast demand-supply imbalance compensation NAS batteries are employed due to their fast charge and discharge capability. They have been satisfactorily applied in the levelling of power outputs fluctuations of wind farms. They also can be used for load levelling and load peak shaving. [21, 22].

In this work, a simplified model of the NAS battery is considered. A first order system with a small time constant of 10 microseconds is used to represent the fast dynamics of this type of batteries.

\section{OPERATION STRATEGY}

The operation strategy is divided in three parts, according to the time frames involved. The overall operation scheme is shown in Figure 3.

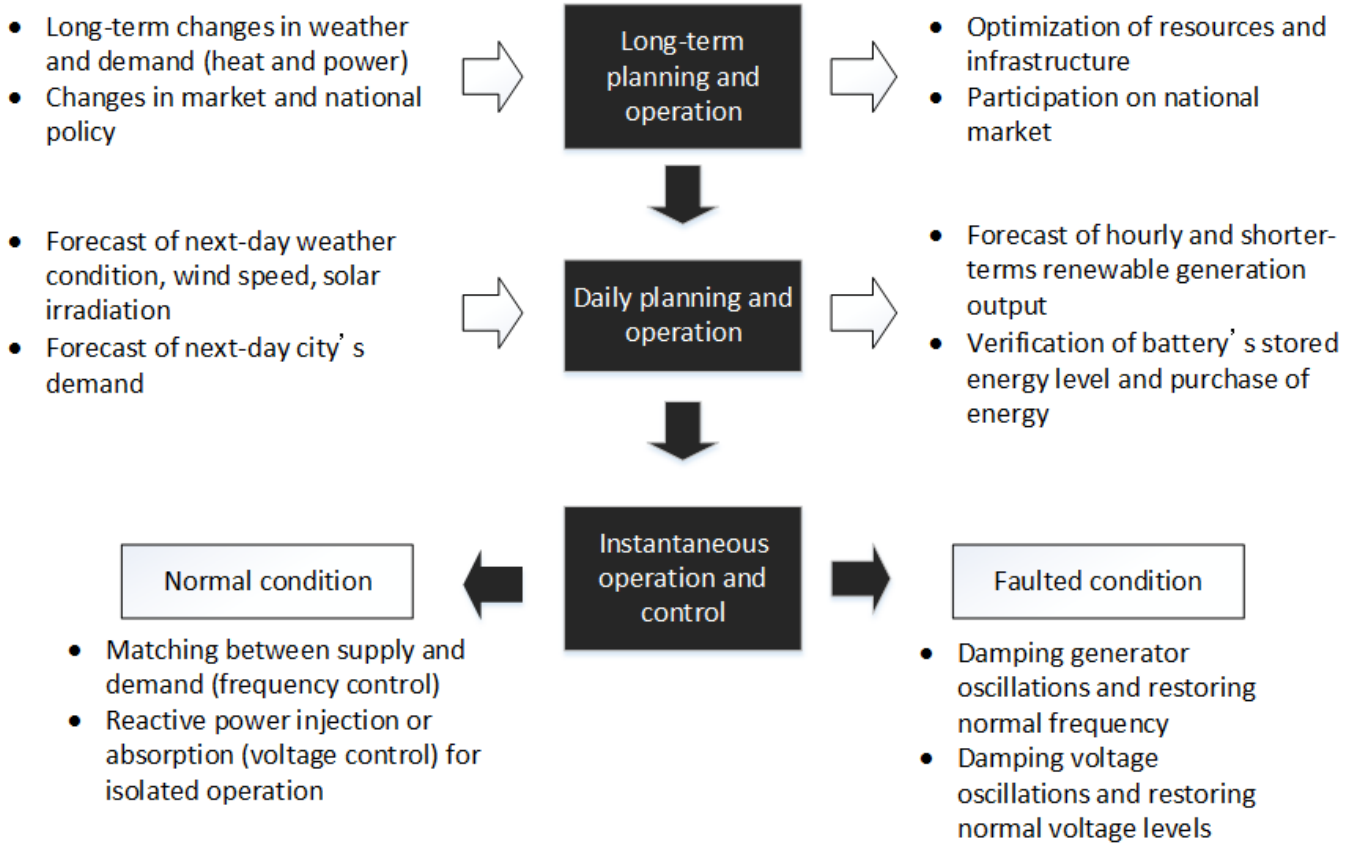

Figure 3. Overall operation scheme

\section{Long-term planning and operation}

In order to determine the optimal utilization of the available resources and infrastructure, together with the strategy for the participation of the proposed system in the national electricity market, careful assessment is necessary, focusing on key elements such as weather change, demand trends and change in the energy policy of the entire country .

From the point of view of available and exploitable resources in the city, hourly-averaged balance evaluation between supply and demand, for one year operation, from April 2012 to March 2013, is presented.

The data affecting the output of the renewable generation units is taken from Japanese meteorological and marine agencies, and from the solar power facilities at Kitami Institute of Technology, Japan. The hourly annual energy demand is divided in demand for light and power, and demand for space heating. The power for heating is assumed to be provided by heat pumps.

\section{Daily planning and operation}

The demand for the city and the generation output of wind, solar and tidal farms are forecast in advance, for one-day operation. These predictions depend directly on the season, weather condition, tidal current and wind speeds, and solar irradiation. 
If the renewable energy to be generated and that stored in the batteries is not enough to supply the forecast demand at any instant in the day the deficit is purchased from the local utility at previously agreed price and time of the day. On the contrary, if there is a surplus of energy, this is sold to the local utility at previously agreed conditions. The net amount of energy interchanged with the local power utility during one year is expected to be equal to zero.

\section{Instantaneous operation and control}

The balance between demand and supply is performed instantaneously and automatically by a controller with optimal characteristics since a certain degree of randomness is involved. If the daily forecast of demand and supply is properly established, the last stage in balancing supply and demand is the instantaneous balance of the outputs of generators and energy storages, and the corresponding demand. The instantaneous balancing controls the frequency of the system. Since the renewable generators are highly uncontrollable, with fast changes that may not be compensated by the conventional generators in the system, the control task is performed on the NAS battery for charge and discharge operations.

Furthermore, during faulted conditions, the NAS battery must be capable of dealing with the disturbance by injecting and absorbing active and reactive power to recover the normal operating condition. In case of isolated operation, wind turbines can support frequency by emulating conventional synchronous generators and by injecting reactive power to the system $[23,24]$. In this paper, only the normal condition case shown in Figure 3 is considered.

Another important parameter of electricity quality, the voltage level, is assumed to be controlled by the local utility. This assumption is valid since the distances involved are short and the relative size of the target system is small.

For the instantaneous control, during normal operating conditions a Model Predictive Control (MPC) approach is considered due the degree of uncertainty and randomness involved, and due to its capability to deal with multiple inputs and multiple outputs, in contrast to conventional proportional-integral controllers [25].

In Figure 4, the actual frequency of the system $f_{-}$sys is compared with the reference frequency $f_{-}$ref of $50 \mathrm{~Hz}$ and a signal is sent to the battery for charging and discharging operation (active power, or $P$ control).

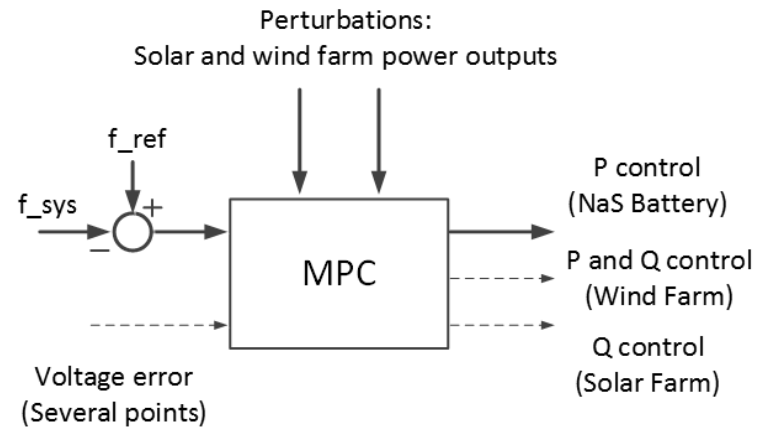

Figure 4. MPC control scheme

The dashed arrows indicate possible inputs and outputs in case of operation of isolated systems where voltage must be entirely controlled by renewable generators (reactive power, or $Q$ control), and the wind turbines can participate in the frequency regulation of the system during abnormal conditions. 


\section{SIMULATION RESULTS}

First, static simulation is used to assess the total annual renewable generation and the total annual demand in the city, based on actual past data. Secondly, dynamic simulations are performed, to evaluate the impact of the intermittent renewable power outputs in the frequency of the system, and to demonstrate the favourable effects of a fast charging-discharging battery in reducing the frequency oscillations and keeping them within permitted ranges.

\section{Annual supply and demand evaluation}

The exploitable renewable power generation together with the annual demand of the city are shown in Figures 5 and 6, respectively. According to results, the total annual demand can be supplied completely by renewable generation. However, shorter-term balances, such as monthly, daily and hourly balances, must be carefully considered in order to define the characteristics of the storage systems needed.

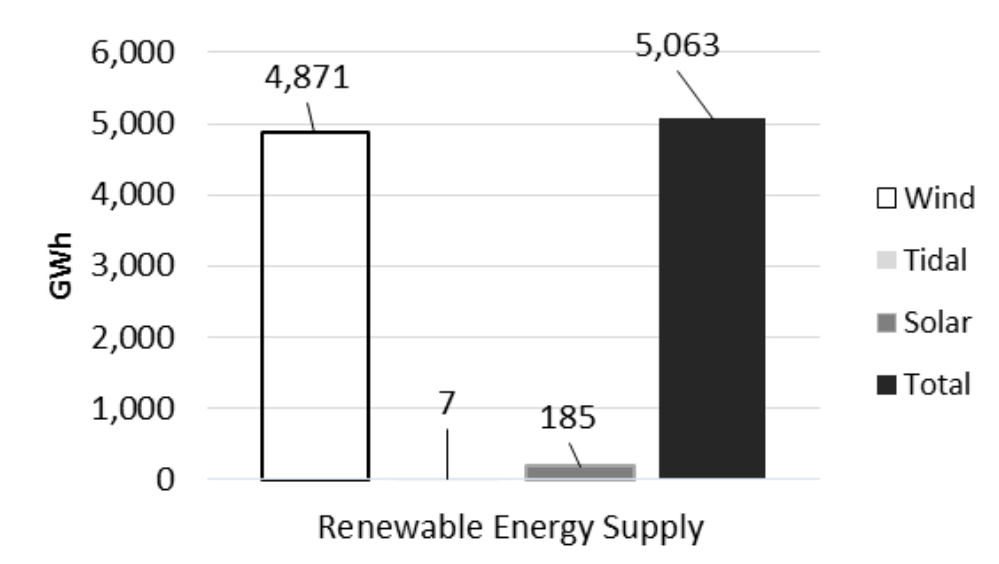

Figure 5. Exploitable renewable energy in Kitami

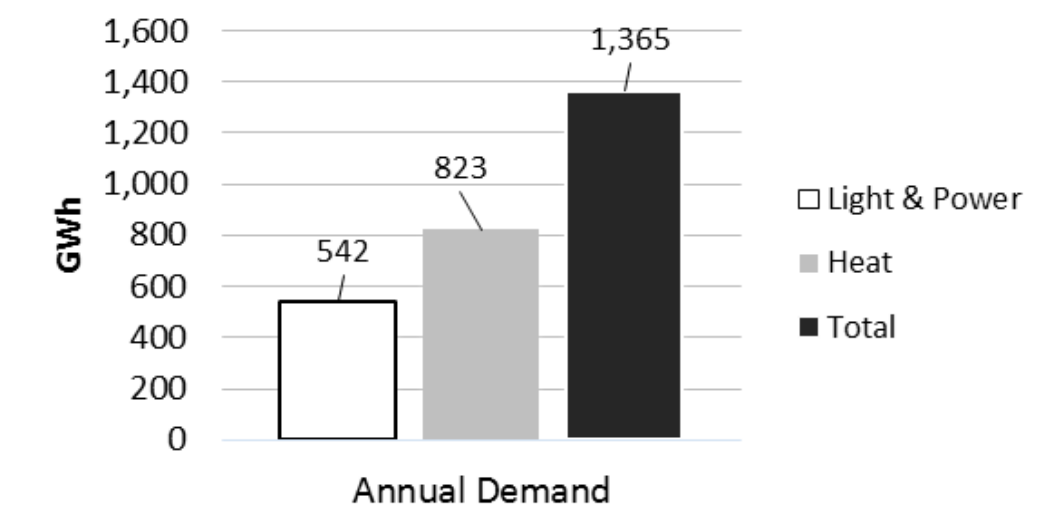

Figure 6. Annual demand of Kitami

\section{Instantaneous energy balance}

Three cases are considered. Step change in wind speed, loss of an important load in the system and random variation in solar irradiation.

In this paper, a proportional-integral controller showed similar results to those of the MPC controller because of the single-input single-output characteristic of the cases analysed. 
Step change in wind speed. In order to capture the impact of the output of the wind farms, a simple step change in wind speed is selected, keeping other outputs constant. Figure 7 shows the power output of the wind farm due to an increase in wind speed from 10 to $15 \mathrm{~m} / \mathrm{s}$, at $t=20 \mathrm{~s}$.

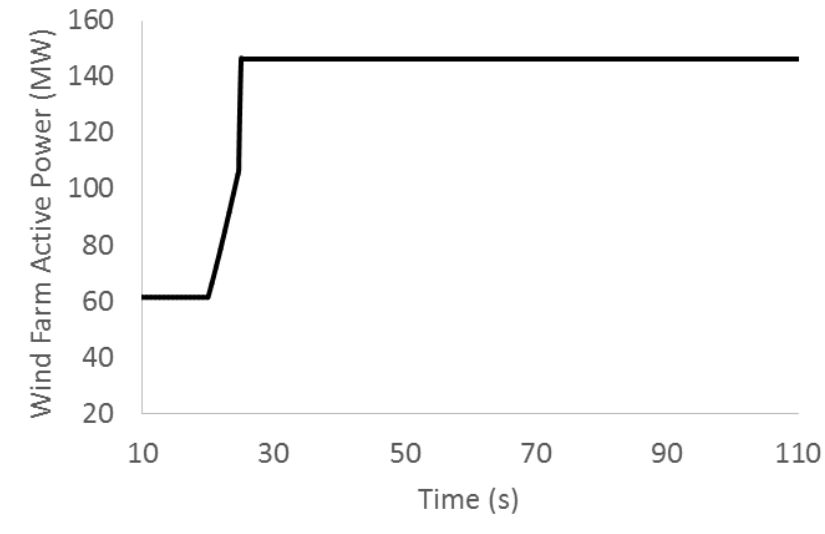

Figure 7. Wind farm power output

It can be noticed that despite the step change in the wind speed the wind turbine output follows a ramp profile. This shows one of the main differences between the characteristics of a wind and a solar farm outputs. Solar farm output follows a much closer profile to the shape in the input due to its lack of inertia.

Figure 8 shows the variations in frequency for the case of wind speed step increase, with and without the action of the controller applied to the NAS battery. Without the support of the fast charging and discharging capability of the battery, the load frequency control (LFC) of the conventional generators is not capable of keeping the frequency within the permitted range of $\pm 0.3 \mathrm{~Hz}$.

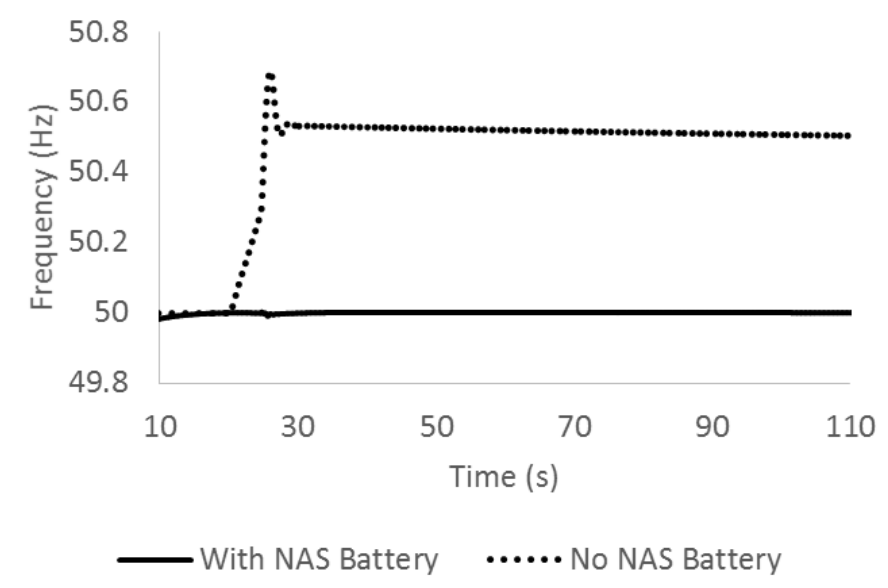

Figure 8. Frequency variation for a step increase in wind speed

Loss of a large load in the system. The loss of a load of $40 \mathrm{MVA}$ at $t=30 \mathrm{~s}$ is simulated in order to analyse a large instantaneous impact on the system. The loss of a generator or a load behaves as step changes in power that affects the total balance in the system.

Figure 9 shows the variations in frequency for the case of a step change in the system's load, with and without the action of the controller applied to the NAS battery.

Here, as in the case of wind step change, the LFC of conventional generators is not capable of keeping the frequency variation within the range of $\pm 0.3 \mathrm{~Hz}$. On the other hand, the fast dynamics of the NAS battery allows the variation to remain bounded in this range. 


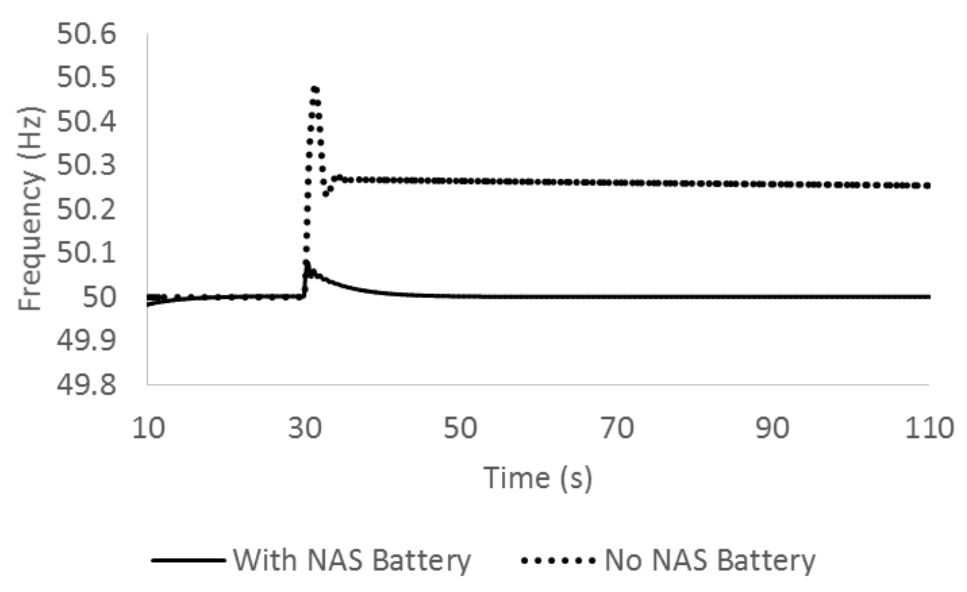

Figure 9. Frequency variation for a loss of load in the system

Figures 10 and 11 show the active power variation of the NAS battery for the two scenarios simulated above. It can be noticed how the NAS battery absorbs satisfactorily the two types of variations in the system, that of wind farm output and that of loss of load.

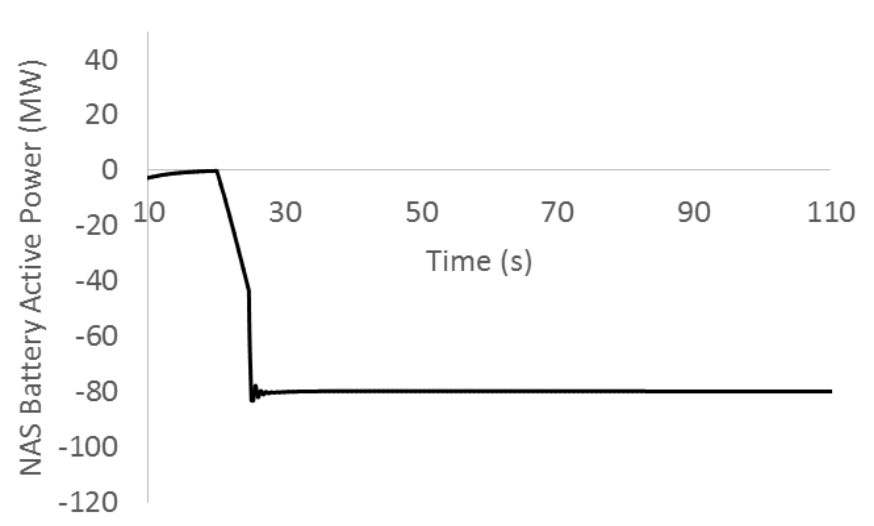

Figure 10. NAS battery active power for a step increase in wind speed

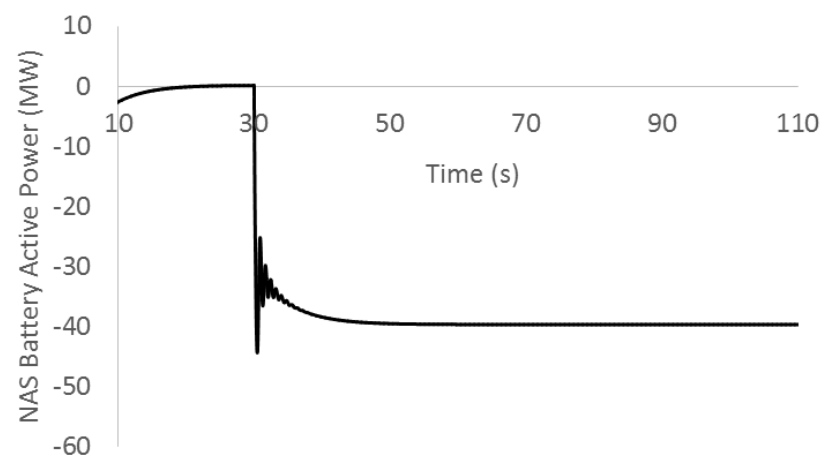

Figure 11. NAS battery active power for a loss of load in the system

Random solar irradiation. A random variation in solar irradiation is considered as the third scenario. The simulations are intended to show how the controller, despite the rapid and random changes, can keep frequency variations within the permitted range of $\pm 0.3 \mathrm{~Hz}$.

Figure 12 shows the power output of the solar farm for random irradiation changes. Due to the fast dynamics of the solar cell, the output follows the random irradiation pattern. 


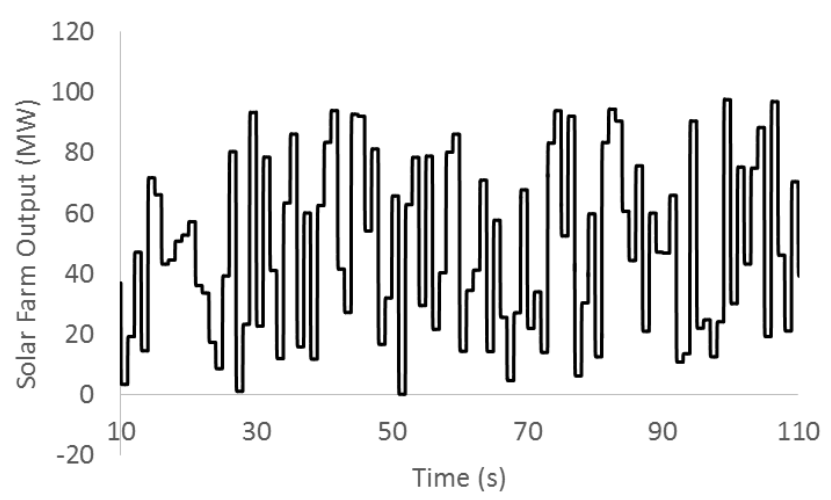

Figure 12. Solar farm power output for random solar irradiation

Figure 13 shows the variation in frequency for the random variation in solar irradiation with and without the action of the controller applied to the NAS battery. It is clear that the LFC of the conventional generators, working without the support of the fast acting NAS battery, is not capable of properly regulating the frequency, due the fast and random changes. The use of a NAS allows the frequency variations to remain within the permitted range.

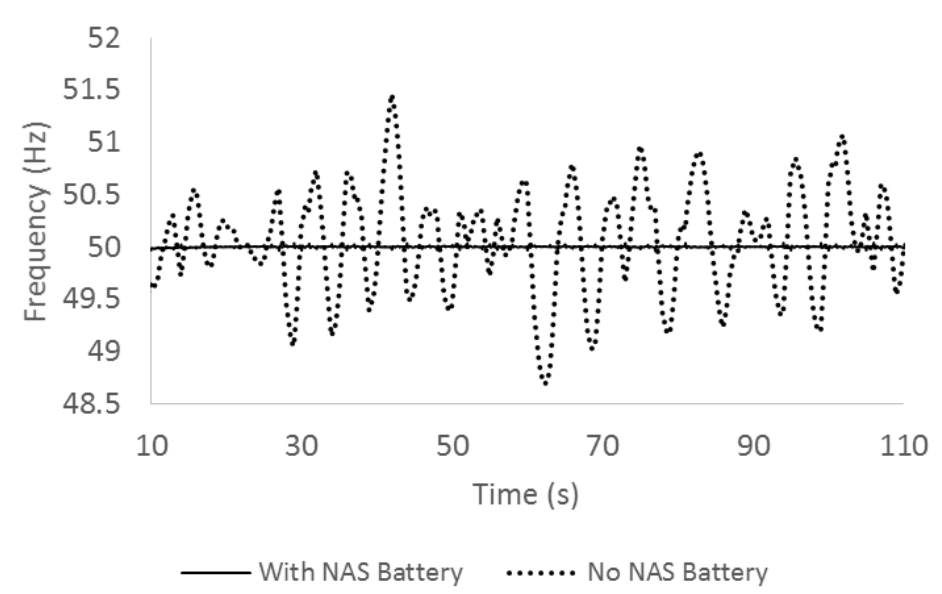

Figure 13. Frequency variation for random solar irradiation

Figure 14 shows the active power absorption or injection for the case of random variation in solar irradiation. It can be seen how fast the NAS battery change the output set point to follow the changes in solar farm outputs.

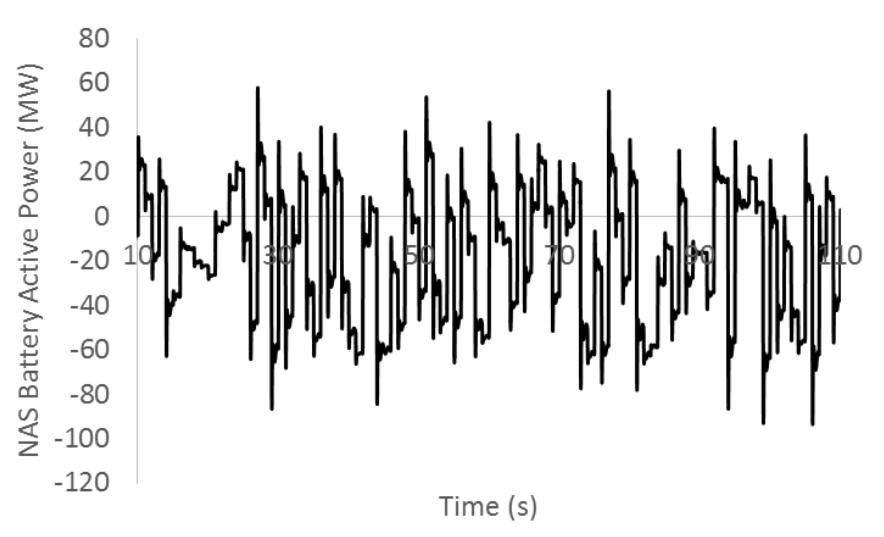

Figure 14. NAS battery active power for random solar irradiation 


\section{CONCLUSION}

In this paper, a strategy for the operation of renewable energy generators and energy storage devices for the development of a clean smart city, with zero $\mathrm{CO}_{2}$ emission, and independent from nuclear generation located at a cold region in Japan, is presented. According to simulations based on actual hourly weather and demand data for one year, the city's annual demand can be supplied entirely by solar, wind and tidal generation.

Instantaneous, daily and long-term operational strategies are proposed. The instantaneous strategy that uses a fast dynamic NAS battery and is based on a MPC approach is detailed and dynamically simulated for changes in selected wind speed and solar irradiation, and for a loss of an important load in the system. According to simulations, despite the highly variable outputs of the intermittent sources, the frequency variations can be kept within the permitted range of $\pm 0.3 \mathrm{~Hz}$ by the proposed control system. A MPC-base control system is suggested as it is capable of dealing with discrepancies between the parameters of real systems and that of models utilized for the controller design, as well as randomness, uncertainties and multiple-input multiple-output control in the system.

The area where Kitami City is located is particularly rich in wind, solar and tidal resources. Although the results presented are not directly applicable to an area with less favourable conditions, the results regarding the instantaneous strategy are still applicable as they are more related to short-term power balance.

Since the studied system is considered connected to the local utility's power grid, the voltage control is assumed performed by this stronger system. For an eventual isolated operation scenario, the voltage control must be performed by renewable generators which have converters that are capable of independently controlling active and reactive power. This constitutes a next stage in the development of a completely flexible zero-emission smart city for Kitami.

\section{NOMENCLATURE}

$f_{-}$ref $\quad$ Frequency Reference $\quad[\mathrm{Hz}]$

$f_{-}$sys $\quad$ System Frequency $\quad[\mathrm{Hz}]$

$P \quad$ Active Power $\quad[\mathrm{MW}]$

$Q \quad$ Reactive Power $\quad[\mathrm{MW}]$

\section{Abbreviations}

$\begin{array}{lll}\text { DFIG } & \text { Doubly Fed Induction Generator } & {[-]} \\ \text { HEPCO } & \text { Hokkaido Electric Power Company } & {[-]} \\ \text { LFC } & \text { Load Frequency Control } & {[-]} \\ \text { MPC } & \text { Model Predictive Control } & {[-]} \\ \text { NAS } & \text { Sodium-sulphur } & {[-]} \\ \text { WT } & \text { Wind Turbine } & {[-]}\end{array}$

\section{REFERENCES}

1. U.S. Department of Energy, Mission, http://www.energy.gov/mission, [Accessed: 24-Feb-2014]

2. European Commission, Energy Strategy for Europe, http://ec.europa.eu/energy/index_en.htm, [Accessed: 24-Febr-2014]

3. SmartGrid.gov, What is a Smart Grid?, https://www.smartgrid.gov/the_smart_grid\#smart_grid, [Accessed: 24-Feb-2014] 
4. Japan Smart Community Alliance, The Operational Experience of Sendai Microgrid in the Aftermath of the Devastating Earthquake: A Case Study, https://www.smart-japan.org/english/reference/13/Vcms3_00000020.html, [Accessed: 24-Feb-2014]

5. Ministry of Economy, Trade and Industry (METI), Annual Report on Energy, Outline of the FY2012 Annual Report on Energy (Energy White Paper 2013), http://www.meti.go.jp/english/report/index_whitepaper.html\#energy, [Accessed: 24-Feb-2014]

6. EnergyPLAN, Advanced Energy System Analysis Computer Model, Aalborg University, http://www.energyplan.eu/about/, [Accessed: 24-Feb-2014]

7. Lund, H., Andersen, A. N., Østergaard, P. A., Mathiesen, B. V., Conolly, D., From Electricity Smart Grids to Smart Energy Systems - A Market Operation Based Approach and Understanding, Energy - The International Journal, Elsevier, Vol. 42, No. 1, pp 96-102, 2012, http://dx.doi.org/ 10.1016/j.energy.2012.04.003

8. Conolly, D., Lund, H., Mathiesen, B. V., Werner, S., Möller, B., Persson, U., Boermans, T., Trier, D., Østergaard, P. A., Nielsen, S., Heat Roadmap Europe: Combining District Heating with Heat Savings to Decarbonise the EU Energy System, Energy Policy, Elsevier, Vol. 65, pp 475-489, 2014, http://dx.doi.org/ 10.1016/j.enpol.2013.10.035

9. Conolly, D., Lund, H., Mathiesen, B. V., Leahy, M., The First Step Towards a 100\% Renewable Energy-system for Ireland, Applied Energy, Elsevier, Vol. 88, No. 2, pp 502-507, 2011, http://dx.doi.org/10.1016/j.apenergy.2010.03.006

10.Obara, S., Development of a Dynamic Operational Scheduling Algorithm for an Independent Micro-Grid with Renewable Energy, Journal of Thermal Science and Technology, The Japan Society of Mechanical Engineers (JSME), Vol. 3, No. 3, pp 474-485, 2008, http://dx.doi.org/10.1299/jtst.3.474

11.U.S. Department of Energy, Microgrids at Berkeley Laboratory, Nagoya 2007, Symposium on Microgrids, Overview of Micro-grid R\&D in Japan, http://der.lbl.gov/sites/der.lbl.gov/files/nagoya_morozumi.pdf, [Accessed: 25-February-2014]

12.Obara, S., Kawai, M., Kawae, O., Morizane, Y., Operational Planning of an Independent Microgrid Containing Tidal Power Generators, SOFCs, and Photovoltaics, Applied Energy, Elsevier, Vol. 102, pp 1343-1357, 2013, http://dx.doi.org/ 10.1016/j.apenergy.2012.07.005

13.Cellura, M., Di Gangi, A., Orioli, A., Assessment of Energy and Economic Effectiveness of Photovoltaic Systems Operating in a Dense Urban Context, Journal of Sustainable Development of Energy, Water and Environment Systems, Issue 1, No. 2, pp 109-121, 2013, http://dx.doi.org/10.13044/j.sdewes.2013.01.0008

14.Quoilin, S., Orosz, M., Rural Electrification through Decentralized Concentrating Solar Power: Technological and Socio-Economic Aspects, Journal of Sustainable Development of Energy, Water and Environment Systems, Issue 1, No. 2, pp 199-212, 2013, http://dx.doi.org/10.13044/j.sdewes.2013.01.0015

15. Ohtaka, T., Iwamoto, S., A Method for Suppressing Line Overload Phenomena Using NAS Battery Systems, Electrical Engineering in Japan, Wiley, Vol. 151, No. 3, pp 19-31, 2005, http://dx.doi.org/ 10.1541/ieejpes.124.363

16.Obara, S., Morizane, Y., Morel, J., Economic Efficiency of a Renewable Energy Independent Microgrid with Energy Storage by a Sodium-Sulfur Battery or Organic Chemical Hydride, International Journal of Hydrogen Energy, Elsevier, Vol. 38, No. 21, pp 8888-8902, 2013, http://dx.doi.org/ 10.1016/j.ijhydene.2013.05.036

17.Obara, S., Morel, J., Microgrid Composed of Three or More SOF Combined Cycles without Accumulation of Electricity, International Journal of Hydrogen Energy, 
$\begin{array}{llllll}\text { Elsevier, } & \text { Vol. 39, No. } \quad \text { 5, }\end{array}$ http://dx.doi.org/10.1016/j.ijhydene.2013.11.102

18.Japan Meteorological Agency, http://www.jma.go.jp/jma/indexe.html, [Accessed: 26-Feb-2014]

19.Hokkaido Electric Power Company, Main Infrastructure, http://www.hepco.co.jp/corporate/ele_power/ele_power.html, [Accessed: 26-Feb-2014] (In Japanese)

20.Tocardo Tidal Turbines, http://www.tocardo.com/, [Accessed: 26-Feb-2014]

21.Tanaka, K., Kurashima, Y., Tamakoshi, T., Recent Sodium Sulfur Battery Application in Japan, Bonneville Power Administration, http://www.bpa.gov/Energy/n/tech/energyweb/docs/Energy\%20Storage/NGK-Paper.P DF, [Accessed: 26-Feb-2014]

22.NGK Insulators Ltd, http://www.ngk.co.jp/english/products/power/nas/, [Accessed: 26-Feb-2014]

23.Mauricio, J. M., Marano, A., Gomez-Exposito A., Martinez Ramos J. L., Frequency Regulation Contribution Through Variable-Speed Wind Energy Conversion Systems, IEEE Transactions on Power Systems, Vol. 24, No. 1, pp 173-180, 2009, http://dx.doi.org/10.1109/TPWRS.2008.2009398

24.Morel, J., Bevrani, H., Ishii, T. and Hiyama, T, A Robust Control Approach for Primary Frequency Regulation Through Variable Speed Wind Turbines, IEEJ Transactions on Power and Energy, Vol. 130, No. 11, pp 1002-1009, 2010, http://dx.doi.org/10.1541/ieejpes.130.1002

25.Bemporad, A., Morarim M., Ricker N. L., Model Predictive Control Toolbox User's Guide, The MathWorks, Inc., 1998. 